\title{
Effects of TCSC on Damping Power System Oscillations
}

\author{
Ghazanfar Shahgholian \\ Department of Electrical \\ Engineering \\ Najafabad Branch, Islamic Azad \\ University, Isfahan, Iran \\ shahgholian@iaun.ac.ir
}

\author{
Mansoor Zinali, Ali A. Amini \\ Department of Electrical \\ Engineering \\ Najafabad Branch, Islamic Azad \\ University, Isfahan, Iran \\ zinali@iaun.ac.ir,amini@iaun.ac.ir
}

\author{
Mehdi Mahdavian \\ Department of Electrical \\ Engineering \\ Naein Branch, Islamic Azad \\ University, Isfahan, Iran \\ mahdavian@naeiniau.ac.ir
}

\begin{abstract}
A TCSC is one of the FACTS devices that can provide fast-acting controls of power on the long ac transmission line over wide range. This paper investigates the effects of the TCSC on damping power system oscillations. In this study, TCSC is represented by its fundamental frequency impedance. For improving the system damping, a supplementary damping controller is considered. Finally, the simulation results of system dynamic performance response for system parameters variation is achieved and discussed.
\end{abstract}

Keywords-damping oscillation; dynamic stability; TCSC; eigenavalue analysis

\section{INTRODUCTION}

A power system is a complex network comprising of numerous generators, variety of loads, transmission lines and transformers. Small disturbances continuously occur on the power system because of small variations in loads and generation. Dynamic stability is the ability of power system to maintain synchronism under such disturbances. The disturbances are considered sufficiently small for linearization of system equations to be permissible.

FACTS technology is an emerging new technology which can be efficiently used in improve the power system stabilit$\mathrm{y}$ and damp the machine oscillations. They can control rapidly and flexibly the transmission line impedance, bus voltages and phase angle between voltages in the power system. Fig. 1 gives an overview of nowadays available network controllers and FACTS-devices [1, 2]. FACTS devices are differentiated into two groups based on their mode of operation: reactive impedance-based devices such as TCSC, SVC and TCPS, and voltage source-based devices such as STATCOM, UPFC and IPFC.

Many papers have been published in the effect of FACTS controller to increase the damping of power system oscillation [3-8]. An approach based on the use of a mix of conventional technology and the FACTS technology in a series capacitive compensation scheme, which has the potential of enhancing power system dynamics presented in [9]. In [10], the analysis of mode controllability is used to select the effective location for TCSC equipped with a PID controller and PID power system stabilizer. A method for optimal locating multi-type FACTS devices based on a new variant of
PSO in order to optimize multi-objective voltage stability problem is presented in [11].

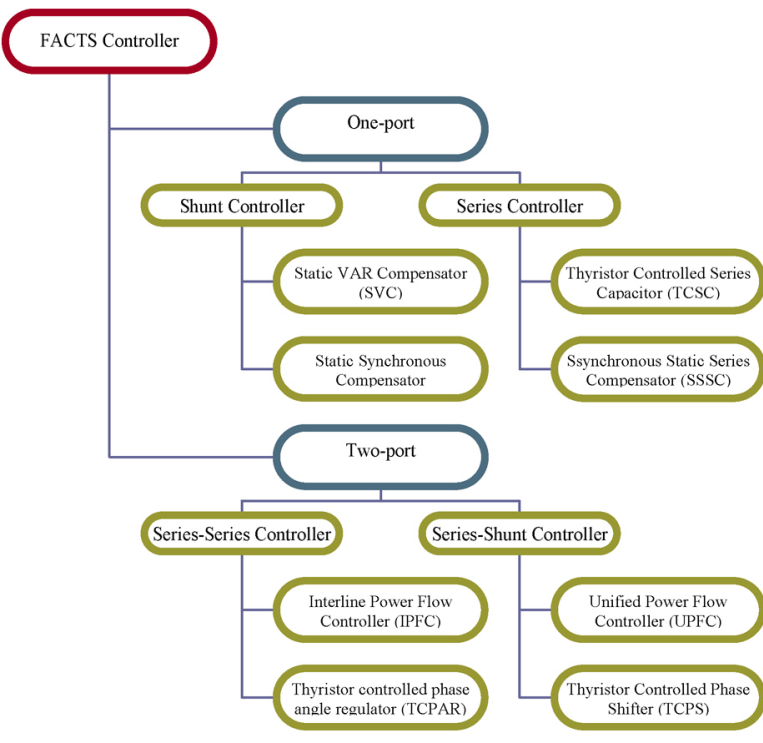

Figure 1. Overview of compensation devices

For analysis small-signal stability, dynamic modeling is necessary for the major components of the power system. In this paper the power system state-space equation and networ$\mathrm{k}$ algebraic equations are developed. The mathematical model of a TCSC in a simple SMIB system is presented. The effect of the proposed controller on system dynamic and improve damping of electromechanical modes of oscillations is investigate. Finally, the simulation results using Matlab verify the effectiveness of the proposed method.

\section{TCSC MODEL}

Variable impedance devices using power electronic technology have the potential to increase power control and system damping. TCSC is one of the most important and best known series FACTS controllers. A TCSC is a seriescontrolled capacitive reactance that is increasingly applied for various reasons by the utilities in modern power system with long transmission lines and remote sources of generations. Suppose a TCSC is located between buses T 
and $\mathrm{B}$ in a transmission line as shown in Fig. 2. When line capacitance is neglected, the total series impedance of the line is $\mathrm{R}_{\mathrm{E}}+\mathrm{j} \mathrm{X}_{\mathrm{E}}$. In general, a TCSC system can be divided into three distinct systems: power circuit; measurement and control systems; firing and synchronization systems. By firing-angle control, TCR current can be controlled from maximum to zero. At the fundamental frequency component, TCR provide a continuously controllable current. The TCSC behaves non-linearly because it changes working point almost continuously. Therefore, the TCSC can be continuously controlled either in capacitive or in inductive area, avoiding the steady-state resonant region.

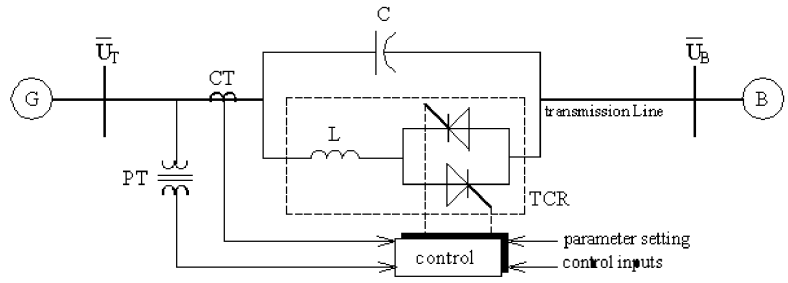

Figure 2. Single-machine infinite-bus power system with TCSC

The ratio of the inserted TCSC reactance to the line reactance is a measure for the compensation degree of the line:

$$
K_{C}=\frac{X_{T}}{X_{E}}
$$

where $\mathrm{X}_{\mathrm{E}}$ is reactance of line and $\mathrm{X}_{\mathrm{T}}$ is reactance of TCSC. The nonlinear relationship between the equivalent reactance of the TCSC at the fundamental frequency and the thyristor conduction angle $(\sigma)$ can be represented as follow as $[12$, 13]:

$$
\begin{gathered}
X_{T}=X_{C}\left[1-\frac{\lambda^{2}}{\lambda^{2}-1} \frac{\sigma+\sin \sigma}{\pi}\right. \\
\left.+\frac{4 \lambda^{2} \cos ^{2}(\sigma / 2)}{\pi\left(\lambda^{2}-1\right)^{2}}\left(\lambda \tan \frac{\lambda \sigma}{2}-\tan \frac{\sigma}{2}\right)\right]
\end{gathered}
$$

where $\lambda$ is the compensation ratio and $X_{C}$ is the nominal reactance of the fixed capacitor $\mathrm{C}$. Reasonable values for $\lambda$ fall in the range of 2 to 4 . The thyristor firing angle is $\alpha=\pi$ $\sigma / 2$. Versus firing angle characteristic is given in Fig. 3, where $\mathrm{X}_{\mathrm{C}}=0.21$ and $\lambda=2$. It shows the one resonant point. The input-output relationships can be seen in Fig. 4 by drawing the three dimensional plot of the control surface versus the two inputs. This plot shows for a given $\lambda$, the value of equivalent reactance $\left(\mathrm{B}_{\mathrm{E}}\right)$ can be controlled by adjusting $\alpha$.

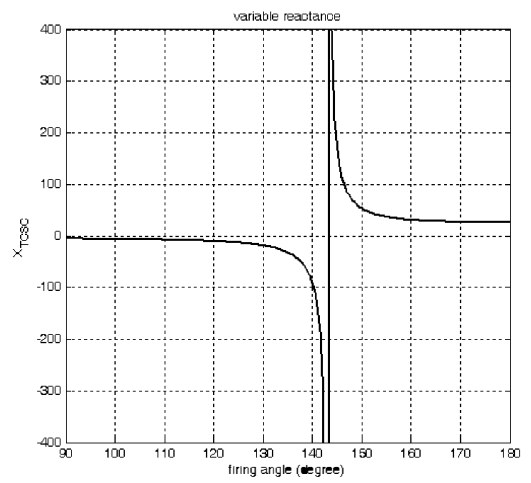

Figure 3. Reactance-firing angle characteristics

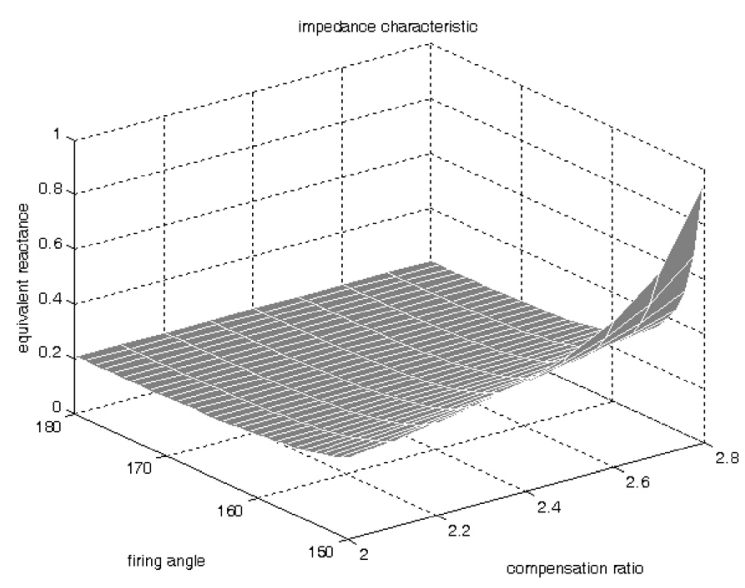

Figure 4. Effect of firing angle and compensation ratio on equivalent reactance

\section{POWER SYSTEM MODEL}

By performing dq transformation, the current through the transmission line can be described by the following equations:

$$
\left\{\begin{array}{l}
i_{d}=\frac{-R_{E} U_{B} \sin \delta-X_{q e} U_{B} \cos \delta+X_{q e} E_{q}^{\prime}}{R_{E}^{2}+X_{q e} X_{d e}^{\prime}} \\
i_{q}=\frac{-R_{E} U_{B} \cos \delta+X_{d e}^{\prime} U_{B} \sin \delta+R_{E} E_{q}^{\prime}}{R_{E}^{2}+X_{q e} X_{d e}^{\prime}}
\end{array}\right.
$$

where $\mathrm{E}_{\mathrm{q}}^{\prime}$ is the generator $\mathrm{q}$-axis transient voltage, $\delta$ is rotor angle, $X^{\prime}{ }_{d}$ and $X_{q}$ are the direct and quadrature reactance of the generator, respectively, and $X_{\mathrm{qe}}=\mathrm{X}_{\mathrm{q}}+\mathrm{X}_{\mathrm{T}}+\mathrm{X}_{\mathrm{e}}$ and $\mathrm{X}_{\mathrm{de}}{ }=\mathrm{X}_{\mathrm{d}}^{\prime}$ $+\mathrm{X}_{\mathrm{T}}+\mathrm{X}_{\mathrm{e}}$. The stator algebraic equations are given by:

$$
\left\{\begin{array}{l}
u_{d}=X_{q} i_{q} \\
u_{q}=E_{q}^{\prime}-X_{d}^{\prime} i_{d}
\end{array}\right.
$$


The synchronous machine is modeled as a third-order model equipped with a simple automatic voltage regulator for excitation control [14]:

$$
\left\{\begin{array}{l}
\frac{d}{d t} \delta=\omega_{o}(\omega-1) \\
\frac{d}{d t} \omega=\frac{1}{2 H}\left(P_{M}-P_{E}-K_{D} \omega\right) \\
\frac{d}{d t} E_{q}^{\prime}=\frac{1}{T_{d o}^{\prime}}\left[E_{F}-E_{q}^{\prime}+\left(X_{d}^{\prime}-X_{d}\right) i_{d}\right] \\
\frac{d}{d t} E_{F}=-\frac{K_{A}}{T_{A}} E_{F}+\frac{1}{T_{A}} U_{A}
\end{array}\right.
$$

where $\mathrm{E}_{\mathrm{F}}$ represents the voltage output voltage proportional to the internal voltage generator, $\omega$ is the rotor speed of the generator, $\mathrm{P}_{\mathrm{M}}$ is the mechanical input power, $\mathrm{K}_{\mathrm{D}}$ is the damping constant, $\mathrm{J}_{\mathrm{M}}$ is the inertia constant and $\mathrm{T}_{\text {do }}^{\prime}$ is direct axis transient open circuit time constant.

\section{LINEARIZED MODEL}

The linearized mathematical model of the power system can obtain by linearizing the system nonlinear equations around a given operating point. Let $\mathrm{X}_{\mathrm{T}}=\mathrm{X}_{\mathrm{TO}}+\Delta \mathrm{X}_{\mathrm{T}}$, where $\mathrm{X}_{\mathrm{TO}}$ is the steady-state set point and $\Delta \mathrm{X}_{\mathrm{T}}$ is the control modulation:

$$
\Delta X_{T}=X_{T O} \frac{-2 \lambda^{2}\left(\cos \sigma_{o}-1\right)}{\lambda^{2}\left(\sigma_{o}-\sin \sigma_{o}\right)-\pi} \Delta \alpha
$$

where $\Delta \alpha$ is the incremental change in the firing angle of the TCSC. At the nominal loading condition, the $\mathrm{d}$ and $\mathrm{q}$ components of the machine current can be written as:

$$
\left\{\begin{array}{l}
\Delta i_{d}=\underbrace{\frac{U_{B} \sin \delta_{o}}{X_{d e o}^{\prime}}}_{K_{d d}} \Delta \delta+\underbrace{\frac{-I_{d o}}{X_{d e o}^{\prime}}}_{K_{d t}} \Delta X_{T}+\frac{1}{X_{d e o}^{\prime}} \Delta E_{q}^{\prime} \\
\Delta i_{q}=\underbrace{\frac{U_{B} \cos \delta_{o}}{X_{q e o}}}_{K_{d e}} \Delta \delta+\underbrace{-\frac{I_{q o}}{X_{q e o}}}_{K_{q t}} \Delta X_{T}
\end{array}\right.
$$

The state space model of the power system with TCSC is given as follows:

$$
\begin{aligned}
\frac{d}{d t} \Delta \omega= & -\frac{K_{D}}{J_{M}} \Delta \omega-\frac{K_{1}}{J_{M}} \Delta \delta-\frac{K_{2}}{J_{M}} \Delta E_{q}^{\prime} \\
+ & \frac{1}{J_{M}} \Delta P_{M}-\frac{K_{P}}{J_{M}} \Delta X_{T} \\
\frac{\mathrm{d}}{\mathrm{dt}} \Delta \delta & =\omega_{\mathrm{o}} \Delta \omega
\end{aligned}
$$

$$
\begin{gathered}
\frac{\mathrm{d}}{\mathrm{dt}} \Delta \mathrm{E}_{\mathrm{q}}^{\prime}=-\frac{\mathrm{K}_{4}}{\mathrm{~T}_{\mathrm{do}}^{\prime}} \Delta \delta-\frac{1}{\mathrm{~K}_{3} \mathrm{~T}_{\mathrm{do}}^{\prime}} \Delta \mathrm{E}_{\mathrm{q}}^{\prime}+\frac{1}{\mathrm{~T}_{\mathrm{do}}^{\prime}} \Delta \mathrm{E}_{\mathrm{F}}-\frac{\mathrm{K}_{\mathrm{Q}}}{\mathrm{T}_{\mathrm{do}}^{\prime}} \Delta \mathrm{X}_{\mathrm{T}} \\
\frac{d}{d t} \Delta E_{F}=-\frac{1}{T_{A}} \Delta E_{F}-\frac{K_{A} K_{5}}{T_{A}} \Delta \delta \\
-\frac{K_{A} K_{6}}{T_{A}} \Delta E_{q}^{\prime}-\frac{K_{A} K_{V}}{T_{A}} \Delta X_{T}+\frac{K_{A}}{T_{A}} \Delta U_{R}
\end{gathered}
$$

Figure 5 block diagram representation of SMIB with TCSC. The direct damping torque contribution by the TCSC is applies to electromechanical oscillation loop of the generator. A diagram illustrating the principle mode of operation of a PSS is given in Fig. 6, where the generator speed deviation from that synchronous frequency is input signal. The state equation governing the power system with two leadlag networks are given by [15]:

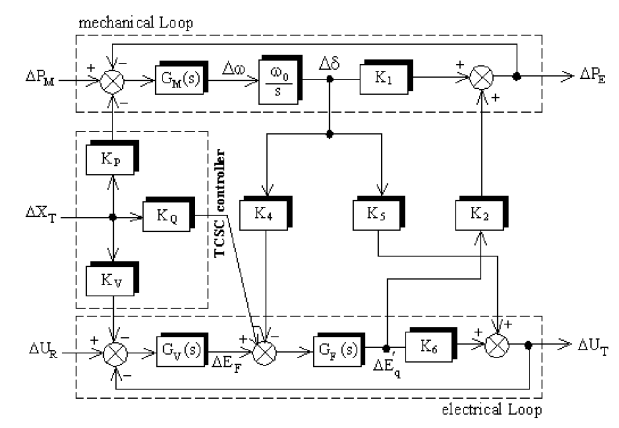

Figure 5. Block diagram of the linearized SMIB model installed with TCSC

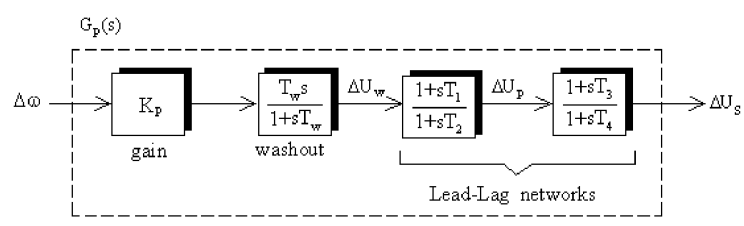

Figure 6. Block diagram of the PSS with two lead-lag networks

$$
\begin{gathered}
\frac{d}{d t} \Delta U_{W}=-\frac{K_{P} K_{1}}{J_{M}} \Delta \delta-\frac{K_{P} K_{D}}{J_{M}} \Delta \omega-\frac{K_{P} K_{2}}{J_{M}} \Delta E_{q}^{\prime} \\
-\frac{1}{T_{W}} \Delta U_{W}-\frac{K_{P}}{J_{M}} \Delta P_{M} \\
\frac{d}{d t} \Delta U_{P}=-\frac{K_{P} K_{1} T_{1}}{J_{M} T_{2}} \Delta \delta-\frac{K_{P} K_{D} T_{1}}{J_{M} T_{2}} \Delta \omega-\frac{T_{1} K_{P} K_{2}}{J_{M} T_{2}} \Delta E_{q}^{\prime} \\
+\left(\frac{1}{T_{2}}-\frac{T_{1}}{T_{2} T_{W}}\right) \Delta U_{W}-\frac{1}{T_{2}} \Delta U_{P}+\frac{K_{P} T_{1}}{J_{M} T_{2}} \Delta P_{M} \\
\frac{d}{d t} \Delta U_{S}=-\frac{K_{P} K_{1} T_{1} T_{3}}{J_{M} T_{2} T_{4}} \Delta \delta-\frac{K_{P} K_{D} T_{1} T_{3}}{J_{M} T_{2} T_{4}} \Delta \omega-\frac{T_{1} T_{3} K_{P} K_{2}}{J_{M} T_{2} T_{4}} \Delta E_{q}^{\prime}
\end{gathered}
$$




$$
\begin{gathered}
+\frac{T_{3}}{T_{4}}\left(\frac{1}{T_{2}}-\frac{T_{1}}{T_{2} T_{W}}\right) \Delta U_{W} \\
+\frac{1}{T_{4}}\left(1-\frac{T_{3}}{T_{2}}\right) \Delta U_{P}-\frac{1}{T_{4}} \Delta U_{S}+\frac{K_{P} T_{1} T_{3}}{J_{M} T_{2} T_{4}} \Delta P_{M}
\end{gathered}
$$

Figure 7 shows a TCSC equipped with a lead-lag controller for improving the system damping. The speed deviation $\Delta \omega$ is considered as the input to the damping controllers. The reference signal is $\mathrm{X}_{\mathrm{TR}}$ and supplementary control signal is $U_{S}$. The output signal of the TCSC is the desired reactance compensation signal, noted as $\mathrm{X}_{\mathrm{T}}$. The TCSC reactance is expressed as:

$$
\frac{d}{d t} X_{T}=-\frac{1}{T_{T}} X_{T}+\frac{K_{T}}{T_{T}}\left(X_{T R}-U_{S}\right)
$$

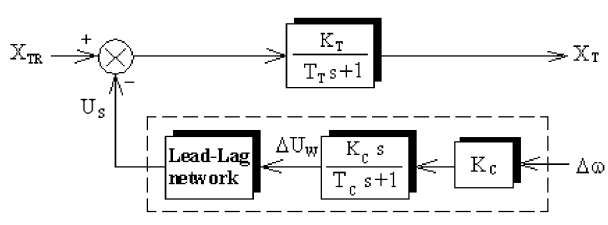

Figure 7. TCSC controller structure

\section{Simulation Results}

Simulation of power systems play a major role in power system planning and operation since stability may affect both its design and operation. Power systems are in general nonlinear systems and the operating conditions can vary over a wide range. The system parameters and loading condition are given in Table I. The system eigenvalues with and without the proposed controller for nominal loading conditions are given in Table II. This base system has a negativelydamped electromechanical mode and needs to be stabilized.

TABLE I. SYSTEM PARAMETERS AND LOADING CONDITION

\begin{tabular}{|c|}
\hline Generator synchronous \\
\hline $\mathrm{J}_{\mathrm{M}}=9.26, \mathrm{~K}_{\mathrm{D}}=0, \mathrm{X}_{\mathrm{d}}^{\prime}=0.19, \mathrm{X}_{\mathrm{d}}=0.973, \mathrm{X}_{\mathrm{q}}=0.55, \mathrm{~T}_{\mathrm{do}}^{\prime}=7.76, \mathrm{f}_{\mathrm{o}}=60$ \\
\hline Exciter system \\
\hline $\mathrm{K}_{\mathrm{A}}=50, \mathrm{~T}_{\mathrm{A}}=0.5$ \\
\hline Normal load \\
\hline $\mathrm{P}_{\mathrm{E} \bullet}=1, \mathrm{Q}_{\mathrm{E} \bullet}=0.015, \mathrm{U}_{\mathrm{T}}=1.05$ \\
\hline Transmission line and shunt load \\
\hline $\mathrm{R}_{\mathrm{E}}=0.034, \mathrm{X}_{\mathrm{E}}=0.997, \mathrm{G}=0.249, \mathrm{~B}=0.262$ \\
\hline $\mathrm{PSS}$ \\
\hline $\mathrm{K}_{\mathrm{P}}=22.7119, \mathrm{~T}_{\mathrm{W}}=1, \mathrm{~T}_{1}=0.1538, \mathrm{~T}_{2}=0.1, \mathrm{~T}_{3}=0.1714, \mathrm{~T}_{4}=0.1$ \\
\hline $\mathrm{TCSC}$ \\
\hline $\mathrm{K}_{\mathrm{C}}=100, \mathrm{~T}_{\mathrm{C}}=1, \mathrm{~T}_{\mathrm{C} 1}=0.0759, \mathrm{~T}_{\mathrm{C} 2}=0.1, \mathrm{~T}_{\mathrm{C} 3}=0.0787, \mathrm{~T}_{\mathrm{C} 4}=0.1$ \\
\hline
\end{tabular}

TABLE II. SYSTEM EIGENVALUE

\begin{tabular}{|c|}
\hline Without PSS and TCSC \\
\hline$\lambda_{1,2}=-10.3642 \pm \mathrm{j} 3.3940, \lambda_{3,4}=0.2659 \pm \mathrm{j} 4.9547$ \\
\hline Only PSS with one lead-lag network \\
\hline$\lambda_{1}=-16.7732, \lambda_{2}=-1.2128$ \\
$\lambda_{3,4}=-1.4913 \pm \mathrm{j} 6.2934, \lambda_{5,6}=-5.1141 \pm \mathrm{j} 2.8732$ \\
\hline Only PSS with two lead-lag networks \\
\hline$\lambda_{1}=-19.7487, \lambda_{2}=-1.1831, \lambda_{3}=-7.3643$ \\
$\lambda_{4,5}=-3.9064 \pm \mathrm{j} 7.4041, \lambda_{6,7}=-2.5439 \pm \mathrm{j} 4.2204$ \\
Only TCSC with controller \\
\hline$\lambda_{1}=-18.4555, \lambda_{2}=-2.5354, \lambda_{3,4}=-11.6507 \pm \mathrm{j} 1.0103$ \\
$\lambda_{5,6}=-2.7040 \pm \mathrm{j} 7.1032, \lambda_{7,8}=-5.7495 \pm \mathrm{j} 7.1032$ \\
\hline
\end{tabular}

The damping of the electromechanical is improved as it change from (-0.0536) to (0.2306) for PSS with one lead-lag network, to (0.5162) for PSS with two lead-lag networks and to $(0.3558)$ with TCSC.

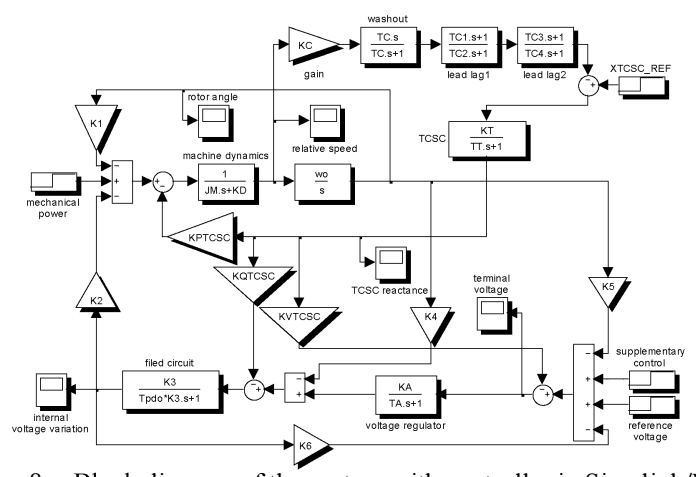

Figure 8. Block diagram of the system with controller in Simulink/Matlab

TABLE III. SYSTEM CONSTANT WITH TCSC

\begin{tabular}{|c|c|c|c|}
\hline Parameter & Value & Parameter & Value \\
\hline $\mathrm{K}_{1}$ & 0.4495 & $\mathrm{~K}_{2}$ & 1.0756 \\
\hline $\mathrm{K}_{3}$ & 0.6466 & $\mathrm{~K}_{4}$ & 0.5078 \\
\hline $\mathrm{K}_{5}$ & -0.0584 & $\mathrm{~K}_{6}$ & 0.7805 \\
\hline $\mathrm{K}_{\mathrm{dd}}$ & 0.6485 & $\mathrm{~K}_{\mathrm{dt}}$ & -0.2927 \\
\hline $\mathrm{K}_{\mathrm{de}}$ & 0.6980 & $\mathrm{~K}_{\mathrm{qd}}$ & 0.2132 \\
\hline $\mathrm{K}_{\mathrm{qt}}$ & -0.4783 & $\mathrm{~K}_{\mathrm{qe}}$ & 0.0132 \\
\hline $\mathrm{K}_{\mathrm{P}}$ & -0.6539 & $\mathrm{~K}_{\mathrm{Q}}$ & -0.2292 \\
\hline $\mathrm{K}_{\mathrm{V}}$ & -0.0669 & & \\
\hline
\end{tabular}

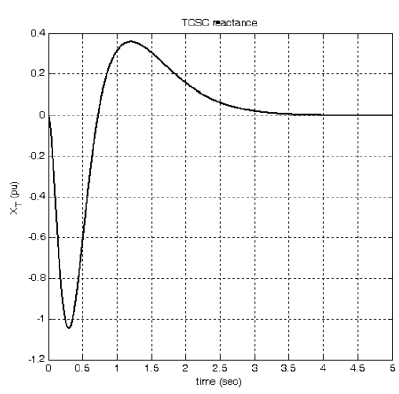

Figure 9. Change in the reactance of the TCSC 


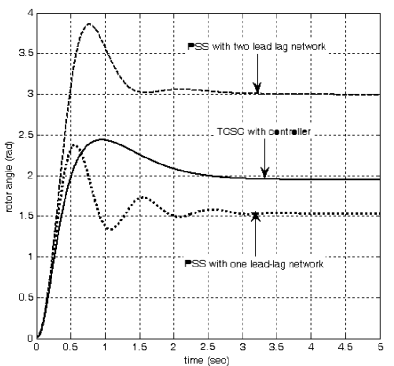

Figure 10. Rotor angle

\section{CONCLUSION}

The TCSC is an effective device for power system control due to its ability to control the continuous variance of the impedance of the transmission line. This paper presents a mathematical model of a TCSC in a SMIB system to investigate the dynamic behavior of the system. The power sensitivity model is used to investigate the damping improvement of the system. Simulation results indicated that the TCSC is capable of significantly improving the damping of the system.

\section{REFERENCES}

[1] A.M. Simoes, D.C. Savelli, P.C. Pellanda, N. Martins, P. Apkarian, "Robust design of a TCSC oscillation damping controller in a weak $500-\mathrm{kV}$ interconnection considering multiple power flow scenarios and external disturbances", IEEE Tran. on Pow. Sys., Vol.24, No.1, pp.226-236, Feb. 2009.

[2] A. Bhaskar, M. Subramani, C. J. Kumar, M. Dash, "Voltage profile improvement using FACTS devices: A comparison between SVC, TCSC and TCPST", IEEE/ARTCOM, pp.890-892, Oct. 2009.
[3] A. Kazemia, B. Badrzadeh, "Modeling and simulation of SVC and TCSC to study their limits on maximum loadability point", Elec. Pow. and Ene. Sys., pp.381-388, 2004.

[4] N. Johansson, L. Angquist, H.P. Nee, "An adaptive controller for power system stability improvement and power flow control by means of a thyristor switched series capacitor (TSSC)", IEEE Trans. on Pow. Sys., Vol.25, No.1, pp.381-391, Feb. 2010.

[5] P.L.So, Y.C.Chu, T.Yu, "Coordinated control of TCSC and SVC for system damping enhancement", Int. Jou. of Con., Auto., and Sys. (IJCAS), Vol.3, No.2, pp.322-333, June 2005.

[6] S. Panda, Multi-objective non-dominated shorting genetic algorithmII. For excitation and TCSC-based controller design", Jou. of Elec. Eng. (JEE), Vol.60, No.2, pp.86-93, 2009.

[7] L.D. Colvara, S.C.B. Araujo, E.B.Festraits, "Stability analysis of power system including facts (TCSC) effects by direct method approach", Elec. Pow. and Ene. Sys., pp.264-274, No.27, 2005.

[8] L. A.S. Pilotto,A. Bianco, W.F. Long, A.Edris, "Impact of TCSC control methodologies on subsynchronous oscillations", IEEE Trans. on Pow. Del., Vol.18, No.1, pp.242-252, Jan. 2003.

[9] D. Rai, G. Ramakrishan, S.O. Faried, A.A. Edris, "Enhancement of power system dynamics using a phase imbalanced series compensation scheme", IEEE Trans. on Pow. Sys., Vol.25, No.2, pp.966-974, May 2010.

[10] P. Bera, D. Das, T.K. Basu, "Tuning of excitation and TCSC-based stabilizer for multimachine power system", Int. Jou. of Eng. (IJE), Vol.23, pp.37-52, Feb. 2010.

[11] R. Benabid, M. Boudour, M.A. Abido, "Optimal placement of FACTS devices for multi-objective voltage stability problem", IEEE/PES, pp.1-11, March 2009.

[12] S. Panda, N. P.Padhy, R.N. Patel, "Genetically optimized TCSC controller for transient stability improvement", Inte. Jour. of Inf. and Sys. Scie. and Eng., pp.19-25, Winter 2007.

[13] H.Li, Q.H.Wu, D.R.Turner, P.Y.Wang, X.X.Zhou, "Modeling of TCSC dynamics for control and analysis of power system stability", Elec. Pow. and Ener. Sys., Vol.22, pp.43-49, 2000.

[14] L.H. Hassan, M. Moghavvemi, H.A.F. Mohamed, "Takagi-surgeon fuzzy gains scheduled PI controller for enhancement of power system stability", Ame. Jou. of App. Sci. (AHAS), Vol.7, No.1, pp.145-152, 2010.

[15] G. Shahgholian, J. Faiz, "The effect of power system stabilizer on small signal stability in single-machine infinite-bus", Int. Jou. of Elec. and Eng., Vol.4, No.2, pp.45-53, 2010. 